\title{
A SENCE OF SAFETY AS AN ELEMENT OF MEDICAL WORKERS RELATIONS MANAGEMENT DURING THE COVID-19 PANDEMIC
}

\author{
Anna ALBRYCHIEWICZ-SŁOCIŃSKA \\ Częstochowa University of Technology, Faculty of Management
}

\begin{abstract}
Ensuring a sense of safety at the place of work is definitely one of the priority aspects of managing medical workers in a crisis situation formed as a result of the COVID- 19 pandemic. Furthermore, care for good employee relations is a special challenge for the managerial staff, taking into consideration the intensity of stress and possibility of conflicts.

Purpose: The aim of the article is to present the views of medical personnel on their sense of safety at work during the COVID-19 pandemic as an element shaping relations among employees.

Design/methodology/approach: The study was carried out in December 2020 on a representative sample of Polish medical workers. It focused on learning their opinions on functioning in the workplace in the conditions of the COVID-19 pandemic. The research was conducted using the CATI method.

Findings: Research results show relations between the sense of safety at work of medical personnel and relations among employees during the COVID-19 pandemic.

Research limitations: The COVID-19 pandemic situation, affecting organizations and society, is unprecedented due to its increase, resources or solutions involved, and the lack of existing literature.

Practical implications: The presented research results emphasized the importance of the sense of safety at work during the COVID-19 pandemic and also indicated the important role of the human resource management in shaping good relations among employees in this crisis situation.

Key words: COVID-19 pandemic, employee relations, human resource management, management in healthcare units, sense of safety at work
\end{abstract}

\section{Introduction}

Resulting in a global crisis, the COVID-19 pandemic set up unprecedented challenges for employers and employees all over the world and the human resource management as well. It is without a doubt that this event constitutes an especially difficult test both in terms of executing the tasks carried out so far, and solving new and complex problems.

Changes in managing organizations and people employed in them affected also the health service sector. Managing medical workers in the face of dangers caused by the pandemic is presented as an interesting research field concerning recent issues (see Kröger 2020, pp. 156-158). Many articles have been devoted to the functioning of medical workers who represent the healthcare systems of various countries (compare Iyengar et al. 2020, pp. 943-946).

https://doi.org/10.11118/978-80-7509-820-7-0029

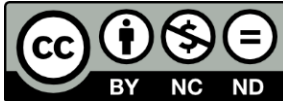


The aim of the article is to present the views of medical personnel on their sense of safety at work during the COVID-19 pandemic as an element shaping relations among employees.

This study contains the results of research concerning selected aspects of human resource management in health care units during a crisis related to COVID-19. In particular, two important issues were analysed: sense of safety in the workplace and employee relations in the organization. The sense of safety falls into a subjective category, and regardless of the type of organisation that employs healthcare professionals commonly exposed to contact with infected or diseased individuals, we feel entitled to compare their opinions (Bostan et al., 2020; Rind et al., 2020; Monterrosa-Castro et al. 2020). A particular role here is assigned to the employer who creates working environment and comfort through organisation and availability of specific measures and information. Due to the risks associated with the performance of work by medical workers during a pandemic, ensuring safety and supporting good employee relations is one of the most important activities of the management staff.

\section{Research Background}

Human resources are the organization's resources in terms of the knowledge, skills and motivation of its employees. However, they can't be equated with the number of people employed because they involve the potential that employees bring to the company. In other words, these are broadly understood competences of the staff that enable the objectives set to be achieved (Wang, He, Mahoney 2009, pp.1265-1285; Sousa, 2017, pp. 395-402).

Today, due to numerous technological and demographic and social changes in the aspect of work, the employee's competence profile is changing and, as a result, the requirements for managers are changing (Robak 2020, pp. 14931-14939). The effectiveness of employees is influenced, among other things, by their attitudes, knowledge and skills, but also by the relationships between individual team members. In the light of the foregoing, the manager's person and competence are of particular importance (Robak 2018, pp. 521-526; Robak 2019, pp. 157-170). Effective communication and positive contacts with employees, shaping attitudes conducive to team integration and openness to others and cooperation in the implementation of tasks, are important in directing. Due to the increasing complexity of work and new organizational and economic dependencies, professional work can rarely be done individually. In the working environment, therefore, a specific arrangement of relationships between people working together to carry out certain tasks is created (Skolik, Robak 2016, pp. 146-149).

The professional relationships established lead to the formation of social bonds between co-workers with an emotional basis. Relationships between team members are a key factor in the efficiency of their work. The friendly atmosphere of the 
company affects the satisfaction and the feeling of fulfilment of the employee (Robak 2017, pp. 569-584).

Relations at work contribute to the achievement of specific objectives and participants in these relations interact with each other and realize individual needs and expectations, as well as common tasks and intentions.

Benefits from positive relations at work are not to be underestimated, since they can be depicted both in individual, and team and organisational context (GlińskaNeweś, et al. 2017, pp. 25-37).

With regard to the organisational profits generated from positive employee relations, their impact on the higher productivity related to effective communication, as well as stimulating employees' commitment and innovativeness should be underlined Whereas, while analysing individual benefits from maintaining good interpersonal relations at work and friendly atmosphere, one should appreciate significance thereof not only in improving job satisfaction, but also in fulfilling the need of affiliation and acceptance, as well as the sense of security (Carmeli, Brueller, Dutton 2009, pp. 81-98; Robertson et al. 2020, pp.596-619).

In a crisis situation, which is working at the healthcare service during the COVID - 19 pandemic, care for good employee relations is a special challenge for the managerial staff, taking into consideration the intensity of stress and possibility of conflicts.

\section{Methodology}

The research results constitute a part of a state-wide quantitative research concerning medical workers carried out in terms of the "Research on the opinion of medical workers concerning their functioning in the conditions of the COVID-19 pandemic in their place of work" program.

The research has been conducted together with a specialist external company, DRB Polonia in December 2020. In order to collect empirical data, the CATI phone survey technique has been used. The research included a randomly selected sample of 384 medical workers, determined on the base of information from GUS. The data showed that the research population of medical workers in 2018 was at 400986 people. The research sample has been selected taking into consideration the representative character of the research population in reference to a division into professional groups.

The following problem has been posed in an assumed research concept: How do medical workers assess the actions of their employers in the field of managing the staff under the conditions of the COVID-19 pandemic.

Referring to the key aspects resulting from managing workers in a crisis situation, the research issues have been detailed into the following:

- providing a sense of safety at the workplace,

- maintaining employee relations.

The STATISTICA program has been used for the purposes of researching the significance of differences in reference to the assumed indicators concerning managing medical workers in a crisis situation related to the COVID-19 pandemic. 
For assessing the significance of differences of analyzsed variables, the following non-parametric tests have been used: Mann-Whitney U test (UMW), KruskalWallis one-way ANOVA test (AKW).

\section{Results and discussion}

The research was conducted among 384 people who are professionally active medical workers, represented specific medical professions. The percentile share of specific professional groups in the research sample was at: doctors (22.4\%), dental doctors $(3.1 \%)$, pharmacists $(7.3 \%)$, nurses $(48.1 \%)$, midwives $(5.7 \%)$, physical therapists $(6.8 \%)$, laboratory diagnosticians $(2.9 \%)$, and medical rescue workers (3.6\%). There were $310(80.73 \%)$ women and $74(19.27 \%)$ men among all 384 interviewees. The interviewees were also diverse in terms of age, seniority in total, as well as work experience in the health service. Taking into account the type of employer's organizations - $269(70.05 \%)$ were public units and $115(29.95 \%)$ non-public facilities.

The respondents were asked to answer detailed research questions using a fivepoint scale. In order to make the analysis easier, the answers were grouped into three main categories, representing the respondent's assessment: negative - the sum of answer 1 and 2, neutral/undecided - answer 3 and positive - the sum of answer 4 and 5.

When asked whether their employer handles functioning in the conditions of a pandemic in reference to ensuring safety at the place of work, most $-68.8 \%$ of the respondents answered positively. Only $10.9 \%$ of respondents stated that their employee operates badly within this scope, and every fifth respondent did not provide a clear answer $(20.03 \%)$.

The answers of respondents to the following question, concerning whether they feel safe at work during the time of the COVID-19 pandemic, are less optimistic because only $46.4 \%$ of the respondents provided positive feelings in this regard. Whereas, $22.4 \%$ of respondents stated that they do not feel safe at work, and almost every third person did not provide a clear answer $(31.2 \%)$. Detailed data on this subject is presented in figure 1.

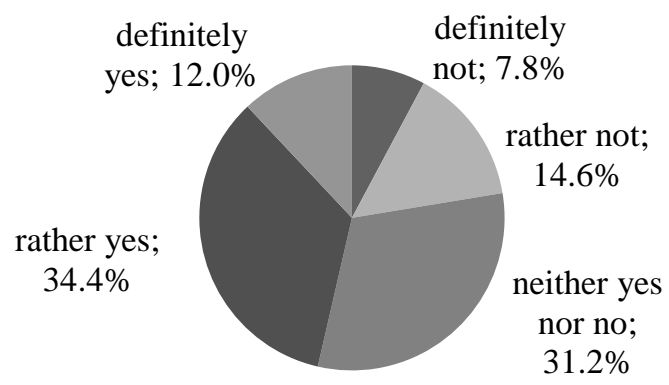




\section{Figure 1. Responses to the question: Do you feel safe in the workplace during the COVID-19 pandemic?}

Source: own research

As it results from collect data, the opinions of medical workers concerning a sense of safety were related to: the type of the employing organization (public, non-public), working in hospital or non-hospital units, employment in COVID-19 dedicated hospitals or non-covid hospitals, as well as living during the pandemic with people for whose health the respondents worry especially and gender as well.

Results of research indicate that according to the opinion of the majority of respondents $(68.8 \%)$ their employer handles it well to function during the COVID19 pandemic in reference to maintaining proper employee relations. Only $10.7 \%$ of respondents had a different opinion, and $20.6 \%$ did not provide a clear answer. Detailed answers are presented in figure 2.

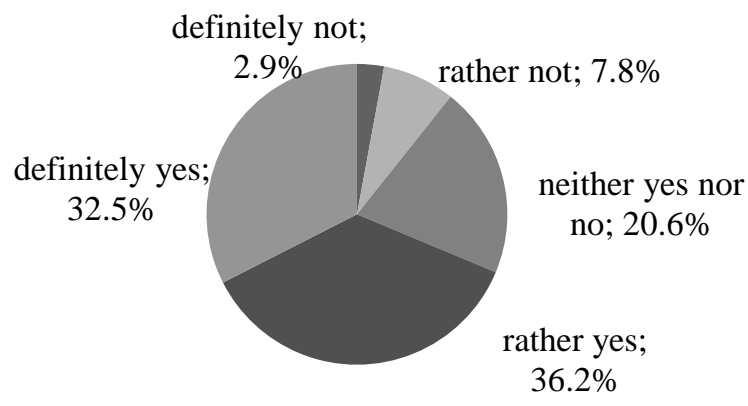

Figure 2. Responses to the question: Does your employer cope with functioning in the conditions of the COVD-19 pandemic with regard to maintaining good employee relations?

Source: own research

The assessments of medical workers concerning relations at the workplace in terms of relations with co-workers were equally positive. As many as $70 \%$ of respondents had positive opinions concerning relations with co-workers, $24.5 \%$ believed those relations to be neither good nor bad, and only $5.7 \%$ perceived this aspect of functioning at the workplace as negative (figure 3 ). 


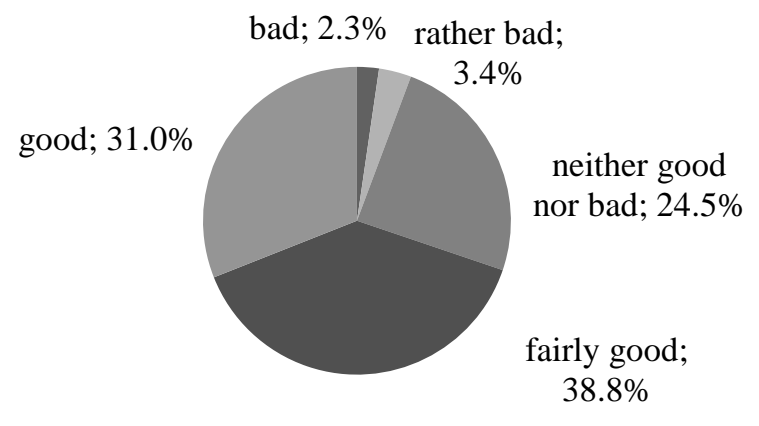

Figure 3. Responses to the question: How do you assess relations in the workplace in terms of: relations with colleagues?

Source: own research

In reference to these results, answers whether during the COVID-19 pandemic a larger number of conflict situations at the workplace has been observed, are also interesting. Most respondents $(40.1 \%)$ confirmed an increase in conflicts among workers, $30.7 \%$ had a different opinion, and $29.2 \%$ did not provide a clear answer (figure 4).

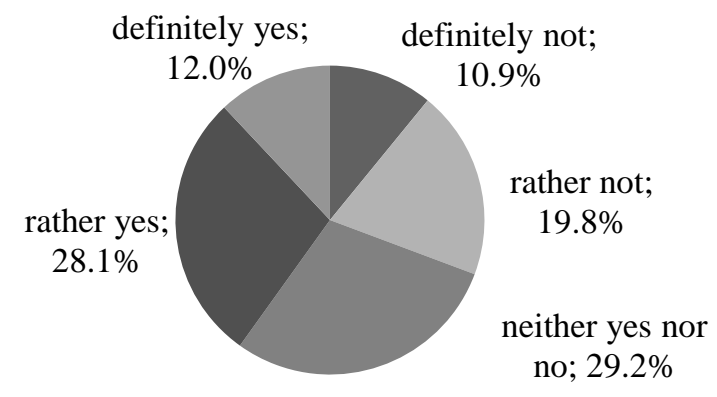

Figure 4. Responses to the question: During the COVID-19 pandemic, did you observe an increased number of conflict situations in the workplace?

Source: own research

Statistical observation revealed also that the answers of respondents to this question have been differentiated due to:

- $\quad$ gender (UMW test $\mathrm{p}=0.0505, \alpha=0.05$ );

- the fact of living during the pandemic with people for whose health they especially worry (UMW test $\mathrm{p}=0.0405, \alpha=0.05$ );

- type of organization employing them - public and non-public (UMW test $\mathrm{p}=0.0200, \alpha=0.05)$. 
A statistical analysis shows that employees of public units confirmed an increase of misunderstandings among co-workers to a greater extent (43.1\%) than respondents from non-public units (33\%). Furthermore, women and respondents living with people for whose lives they were especially worried indicated conflicts between employees relatively more often.

The crisis situation related to the COVID-19 pandemic surely constitutes a new, difficult experience for medical workers, and it affects their opinions concerning the functioning at the workplace, as well as mental condition. The conducted observations correspond with the presented research results of other authors presented in source literature. An interesting reference consists in a work by De los Santos and Labrague (2021) indicating that nurses are characterized by an average or high fear of COVID-19, and the female gender is correlated with the fear of the virus. Moreover, as the fear of COVID-19 increases, so does the professional stress of nurses as well as their intentions of organizational rotation and will to leave work. Initiatives for medical workers at Italian hospitals, aimed at ensuring their safety, but also a sense of affiliation and emotional support, are undoubtedly an attempt to answer these challenges. The practices undertaken there served to strengthen the sense of being a part of a coherent team with common goals, and facilitated expressing thoughts and emotions through short informal talks in small groups or the support of a psychologist (Lissoni et al. 2020, pp. 105-107).

\section{Conclusion}

Research results show relations between the sense of safety at work of medical personnel and relations among employees during the COVID-19 pandemic.

The presented research results emphasized the importance of the sense of safety at work during the COVID-19 pandemic and also indicated the important role of the managerial staff in shaping good relations among employees in this crisis situation.

Working out the proper methods of managing medical workers in a crisis situation conditioned by the COVID-19 pandemic, due to its unique, global, and long-lasting character - is surely not an easy task. However, this skilful help for the staff as well as initiatives in favour of forming proper employee relations may turn out to be the key factors that will translate into increased trust towards employers and identifying with the organization.

\section{References}

1. Bostan S., Akbolat M., Kaya A., Ozata M., Gunes D. (2020). Assessments of Anxiety Levels and Working Conditions of Health Employees Working in COVID-19 Pandemic Hospitals. "Electronic Journal of General Medicine", Vol 17(5):em246, https://doi.org/10.29333/ejgm/8228.

2. Carmeli A., Brueller D., Dutton J.E. (2009), Learning Behaviours in the Workplace: The Role of High-quality Interpersonal Relationships and Psychological Safety, ,Systems Research and Behavioral Science”, 26 (1), pp. 81-98, https://doi.org/10.1002/sres.932. 
3. De los Santos J.A.A., Labrague L.J. (2021), The Impact of Fear of COVID-19 on Job Stress, and Turnover Intentions of Frontline Nurses in the Community: A Cross-Sectional Study in the Philippines, "Traumatology", online publication. doi: 10.1037/trm0000294.

4. Glińska-Neweś A., Sudolska A., Wińska J., Furmańska-Maruszak A. (2017), How Positive Relationships at Work Stimulate the Innovation Orientation of Social Enterprises and ForProfit Organizations, „Annales Universitas Mariae Curie-Skłodowska. Oeconomia”, Lublin, 51 (3), pp. 25-37.

5. Iyengar K., Mabrouk A., Jain V. K., Venkatesan A., Vaishya R. (2020), Learning opportunities from COVID-19 and future effects on health care system, "Diabetes and Metabolic Syndrome", 14(5), pp. 943-946, https://doi.org/10.1016/j.dsx.2020.06.036.

6. Kröger Ch. (2020), Shattered social identity and moral injuries: Work-related conditions in health care professionals during the COVID-19 pandemic, "Psychological Trauma: Theory, Research, Practice, and Policy", 12(S1), pp. 156-158 https://doi.org/10.1037/tra0000715.

7. Lissoni B., Del Negro S., Brioschi P., Casella G., Fontana I., Bruni C., Lamiani G. (2020), Promoting resilience in the acute phase of the COVID-19 pandemic: Psychological interventions for intensive care unit (ICU) clinicians and family members, „Psychological Trauma: Theory, Research, Practice, and Policy”, 12(S1), pp. 105-107. doi.org/10.1037/tra0000802.

8. Monterrosa-Castro A., Redondo-Mendoza V., Mercado-Lara M. J. (2020). Psychosocial factors associated with symptoms of generalized anxiety disorder in general practitioners during the COVID-19 pandemic. "The Journal of Investigative Medicine", Vol 68, 12281234, https://doi:10.1136/jim-2020-001456.

9. Rind E., Kimpel K., Preiser, C., et al. (2020). Adjusting working conditions andevaluating the risk of infection during the COVID-19 pandemic in different workplace settings in Germany: a study protocol for an explorative modular mixed methods approach. "BMJ Open", Vol 10:e043908, https://doi:10.1136/bmjopen-2020-043908.

10. Robak E. (2017), Expectations of generation Y connected with shaping the work-life balance. The case of Poland, „Oeconomia Copernicana”, 8 (4), pp. 569-584, https://doi.org/10.24136/oc.v8i4.35.

11. Robak E. (2018), Factors Influencing the Relations between Employees from Generation $Y$ and their Superiors, Book of Proceedings, ICoM 2018, 8th International Conference on Management, In: Bylok F., Albrychiewicz-Słocińska A., Cichobłaziński L. (ed.), Leadership, Innovativeness and Entrepreneurship in a Sustainable Economy, pp. 521-526, Wydawnictwo Wydziału Zarządzania Politechniki Częstochowskiej, Częstochowa.

12. Robak E. (2019), Expectations of Representatives of the Youngest Generations on the Labor Market Regarding Relations with Superiors, „Przedsiębiorczość i Zarządzanie”, 20 (3), I. 6, pp. 157-170.

13. Robak E. (2020), Relationships with the Superior as an Element of an Organisation's Employer Branding Communication - the Example of Poland, In: Soliman Khalid S. (ed.), Education Excellence and Innovation Management: a 2025 Vision to Sustain Economic Development during Global Challenges, pp. 14931-14939, International Business Information Management Association (IBIMA), Norristown.

14. Robertson K. M., O’Reilly J., Hannah D. R. (2020), Finding meaning in relationships: The impact of network ties and structure on the meaningfulness of work, "The Academy of Management Review”, 45, pp. 596-619, http://doi.wiley.com/10.1002/tie.21989.

15. Skolik S., Robak E. (2017), Factors Shaping Cooperation in Formal Organizations and Informal Social Movements, In: Daroczi M., Robak E., Vinogradov S. (ed.), Management, Organizations and Society, pp. 11-24, Agroinform Publishing House, Budapest, https://doi.org/

10.18515/dBEM.M2017.n01.ch01. 
16. Sousa M.J. (2017), Human Resources Management Skills Needed by Organizations, In: Benlamri R., Sparer M. (ed.), Leadership, Innovation and Entrepreneurship as Driving Forces of The Global Economy, Springer International Publishing AG, Dubai, https://doi.org/10.1007/978-3-319-43434-6_33.

17. Wang H., He J., Mahoney J. (2009), Firm-specific knowledge resources and competitive advantage: the roles of economic and relationship-based employee governance mechanisms, „Strategic Management Journal”, 30 (07-0103), pp.1265-1285, https://doi.org/10.1002/smj.787.. 